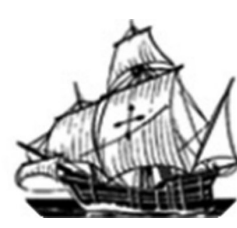

\title{
O efeito das lágrimas como fator de mudança do gênero masculino - um estudo de alguns contos de Mia Couto
}

\author{
Sueder Santos de Souza
}

Resumo: O presente trabalho trata das questões "lacrimosas" encontradas em alguns contos de Mia Couto; a questão da analogia, estabelecida pelo senso comum, entre o choro e a figura da mulher, intrinsecamente ligada à imagem social do gênero feminino. Sendo a lágrima um símbolo socialmente atribuído à sensibilidade feminina e, portanto, excluído do universo masculino - visto que "homens não choram" -, perante o contexto social, a ausência da lágrima é fator que assegura a sexualidade e virilidade do macho. Assim é que a imagem masculina acaba por não fazer parte deste símbolo que, em geral, revela um lado tido como inferior e fraco. É nesse contexto que o autor vai operacionalizar a desconstrução dos pressupostos patriarcais, facultando ao gênero outrora tido como "superior" a possibilidade do choro, da emoção, da sensibilidade a que será encaminhado na medida em que se expuserem às lágrimas das mulheres, sejam de alegria ou de tristeza. Por meio dessa sensibilização proporcionada pelas lágrimas, será possível visualizar o escopo de uma "mudança" positiva para o gênero masculino.

Palavras-chave: lágrimas; Gênero; Mia Couto; feminismo.

Abstract: The present work deals with issues "tearful" found in some tales Mia Couto, the question of analogy, established by common sense, between crying and the woman's figure, inextricably linked to social image of women. Being a symbol tear socially assigned feminine sensitivity and therefore excluded from the male universe - because "men do not cry" - before the social context is the absence of tear factor that ensures male sexuality and virility. Thus the male image turns out not to be part of this symbol usually reveals a side taken as bottom and weak. It is in this context that the author will operationalize the deconstruction of patriarchal assumptions, providing the genre once considered "superior" the possibility of crying, emotion, sensitivity to which it forwards to the extent that it exposes the tears of women, whether joy or sorrow. Through this awareness provided by the tears will be able to see the scope of a "change" positive for males.

Keywords: tears; Gender; Mia Couto; feminism. 


\section{Introdução}

Mia Couto é um autor que trabalha muito bem o fascínio e o terror que a mulher (ou o feminino) provocam no homem, como também a violência com que o homem devolve essa provocação. Assim, nos livros $O$ Fio da Missangas, Contos do Nascer da Terra e Na Berma de Nenhuma Estrada e Outros Contos, o autor tratará em alguns contos sobre as questões "lacrimosas" em que será possível ter uma visão mais clara do que seria a lágrima e do que ela representaria para a figura masculina. Bem como em outros livros, como Jesusalém ou Antes de nascer o mundo, Mia Couto cria personagens que se isolam em um rincão da terra longe da presença de mulheres. O livro começa mais ou menos com "A primeira vez que eu vi uma mulher eu tinha onze anos, e me surpreendi subitamente tão desarmado que desatei a chorar." - percebemos que o que esse personagem vive, tendo visto uma mulher pela primeira vez, é, em certa medida, a mesma coisa que todo homem vive diante de uma mulher. Essa sensação de não conseguir defender-se de toda beleza que emana dela, mas também, e talvez isso seja o mais importante, de todos os afetos que são despertados no interior dos homens em contato com essa exuberância do feminino. Ao longo do livro, a misoginia do pai em contraposição ao fascínio do filho pelo sexo feminino, não se deixando enganar, pai e filho representam facetas complementares do que a presença do feminino provoca nos homens. As lágrimas entrarão nesse jogo, principalmente na necessidade dos homens de ferir essa presença que provoca tanto descontrole neles mesmos. Seria então a lágrima, símbolo que daria acesso ao homem a um lugar diferente do que mostra ou representa a sociedade?

\subsection{Estudo do Gênero: Um breve histórico}

Ao longo do tempo, o senso comum utilizou de forma figurada quaisquer termos relacionados ao Gênero para evocar traços de caráter ou traços sexuais. 
Por exemplo, a utilização proposta pelo Dicionário da Língua Francesa de 1876: "Não se sabe qual é o seu gênero, se é macho ou fêmea, fala-se de um homem muito retraído, cujos sentimentos são desconhecidos”. E Gladstone fazia esta distinção em 1878: "Atena não tinha nada do sexo, a não ser gênero, nada de mulher a não ser forma". Mais recentemente - recentemente demais para que possa encontrar seu caminho nos dicionários ou na enciclopédia das ciências sociais - as feministas começaram a utilizar a palavra "gênero" mais seriamente, no sentido mais literal, como uma maneira de referir-se à organização social da relação entre os sexos. (SCOTT, 1989. p. 2)

Ainda segundo Scott (1989), se pensarmos na gramática e a sua relação com o Gênero, é, ao mesmo tempo "explícita e cheia de possibilidades inexploradas". Faz-se explícita pelo uso gramatical implicar em regras formais que utilizam de designações de masculino ou feminino e, cheia de possibilidades inexploradas, pois em vários idiomas indo-europeus, existe um terceiro sexo, que pode ser definido como neutro ou indefinido. A gramática reconhece Gênero como um meio de classificar fenômenos, um sistema socialmente acordado, mais do que uma descrição objetiva de traços inerentes "sabendo que as classificações surgem de uma relação entre categorias que permite distinções ou agrupamentos separados" (SCOTT, 1989. p. 3).

O termo Gênero aparece primeiro entre as feministas, o texto "Gênero e História das Mulheres: diálogos conceituais", da historiadora Andressa Andrade (2012), aborda como surgiu o conceito Gênero que, segundo suas fontes, teve seu início na década de 70, com os movimentos feministas norte-americanos em busca de uma igualdade entre os sexos, limitando essas diferenças apenas no âmbito biológico. Além disso, ela relata a importância que o conceito Gênero vem ampliando e incluindo outros, como raça, etnias, classe e sexualidade.

A palavra indicava uma rejeição ao determinismo biológico implícito no uso de termos como "sexo" ou "diferença sexual". O gênero sublinhava também o aspecto relacional das definições normativas das feminilidades. As que estavam mais preocupadas com o fato de que a produção dos estudos femininos centrava-se sobre as mulheres de forma muito estreita e isolada, utilizaram o 
termo "gênero" para introduzir uma noção relacional no nosso vocabulário analítico.

É feito então, um reforço à ideia de que o conceito Gênero surge para desconstrução do homem como dominador e a mulher perca o perfil de dominada. Tendo em vista que somos frutos de nossas culturas, as quais são originadas pela sociedade, que influenciam e separam não só biologicamente, mas culturalmente o homem da mulher, limitando esta figura feminina somente a refletir uma imagem da maternidade e da sexualidade e o homem a uma imagem de sujeito dotado de superioridade diante da sociedade.

Ainda em seu uso recente, a designação Gênero está cada vez mais atrelada à imagem da mulher, retomando Scott:

\begin{abstract}
Nessas circunstâncias, o uso do termo "gênero" visa indicar a erudição e a seriedade de um trabalho porque "gênero" tem uma conotação mais objetiva e neutra do que "mulheres". O gênero parece integrar-se na terminologia científica das ciências sociais e, por consequência, dissociar-se da política - (pretensamente escandalosa) - do feminismo. Neste uso, o termo gênero não implica necessariamente na tomada de posição sobre a desigualdade ou o poder, nem mesmo designa a parte lesada (e até agora invisível). Enquanto o termo "história das mulheres" revela a sua posição política ao afirmar (contrariamente às práticas habituais), que as mulheres são sujeitos históricos legítimos, o "gênero" inclui as mulheres sem as nomear, e parece assim não se constituir em uma ameaça crítica. (SCOTT, 1989. p. 5)
\end{abstract}

Este é apenas um aspecto dos muitos que competem ao termo Gênero. $\mathrm{O}$ termo é utilizado também para informações a respeito de mulheres, que, implica também no estudo do outro sem haver uma separação difundida. A ideia de que o mundo feminino pertence ao mundo masculino é criada dentro e por esse mundo. Essa ideia de mundos diferentes remete que "estudar as mulheres de forma separada perpetua o mito de que uma esfera, a experiência de um sexo, tem muito pouco ou nada a ver com o outro sexo" (SCOTT, 1989. p. 7).

Gênero então remete a uma designação de utilização ao que desrespeita as relações sociais entre os sexos, o seu uso rejeita explicitamente as justificativas biológicas "como aquelas que encontram um denominador comum para várias 
formas de subordinação no fato de que as mulheres têm filhos e que os homens têm uma força muscular superior" (SCOTT, 1989. p. 9).

O gênero se torna, aliás, uma maneira de indicar as "construções sociais" - a criação inteiramente social das idéias sobre os papéis próprios aos homens e às mulheres. É uma maneira de se referir às origens exclusivamente sociais das identidades subjetivas dos homens e das mulheres. O gênero é segundo essa definição, uma categoria social imposta sobre um corpo sexuado. Com a proliferação dos estudos do sexo e da sexualidade, o gênero se tornou uma palavra particularmente útil, porque ele oferece um meio de distinguir a prática sexual dos papéis atribuídos às mulheres e aos homens. (SCOTT, 1989. p. 11)

\section{Símbolo Lágrima e o "Acesso" ao Gênero Masculino}

Começaremos então a analisar alguns contos presentes nas obras do autor Mia Couto, que trata sobre uma discussão que envolve tanto a psicologia, a psicanálise, a linguística, a história - como vimos na introdução, indispensável para entendimento do mesmo - e a literatura, a tratar de uma questão específica: o símbolo da lágrima, presente em alguns contos de Mia Couto, remetendo-nos analogamente a uma imagem estabelecida pelo senso comum, entre o choro e a figura da mulher, intrinsecamente ligada à imagem social do gênero feminino. Sendo a lágrima um símbolo socialmente atribuído à sensibilidade feminina e, portanto, excluído do universo masculino - visto que "homens não choram" -, perante o contexto social, a ausência da lágrima é fator que assegura a sexualidade e virilidade do macho. Assim é que a imagem masculina acaba por não fazer parte deste símbolo que, em geral, revela um lado tido como inferior e fraco. É nesse contexto que o autor vai operacionalizar a desconstrução dos pressupostos patriarcais, facultando ao gênero outrora tido como "superior" a possibilidade do choro, da emoção, da sensibilidade a que será encaminhado na medida em que se expuserem às lágrimas das mulheres, sejam de alegria ou de tristeza. Por meio dessa sensibilização proporcionada pelas lágrimas, será possível visualizar o escopo de uma "mudança" positiva para o gênero masculino. $\mathrm{O}$ seu poder, que encontramos em elementos das narrativas propostas 
pelo autor, é de estrema relevância para obtermos uma maior significância não só da lágrima, mas sim do que ela pode contribuir em relação à sensibilidade do homem.

O conto intitulado "Lágrima para irmãos siameses", do livro Contos do Nascer da Terra, gira em torno da história de dois irmãos siameses Osório e Irrisório, ligados por um braço, que se apaixonaram pela mesma mulher. Os dois, desde pequenos, eram muito cúmplices e amigos e sempre disseram que nunca se "separariam"; o pai deles sempre defendeu que o melhor era que se separassem, porque previa que quando se apaixonassem haveria problemas. E o inevitável aconteceu: os dois irmãos apaixonaram-se pela mesma miúda, e, apesar de sempre terem acordado que jamais se separariam, chegou o momento em que tiveram de fazer a escolha. Osório se apaixonou por Marineusa - os irmãos entraram em um consenso para que um pudesse namorar tranquilamente sem a interferência do outro - até um dia que, em suas relações sexuais, Osório sentira um braço involuntário apalpando a moça, então os irmãos puseram-se a brigar. Marineusa então pranteou, magoada. Osório lhe pedira explicações e então Marineusa the mostrou uma lágrima na ponta dos dedos e ele pôs-se maravilhado, vendo na lágrima de sua amada seu próprio rosto, ainda afirmando para ele que esta seria a verdade saída de seu coração. Osório ficou com aquela dúvida e, em outra ocasião, ele voltou a questionar a miúda: "Você, afinal: de quem gosta mais de mim?" Imediatamente Marineusa se pôs em prantos, falando em lágrimas. Logo, Osório exigiu-lhe outra lágrima - como prova de seu amor - ela hesitou, ele gritou com ela exigindo. Logo ele a ameaçou e ela cedeu, deu-lhe uma lágrima e Osório viu seu irmão, e mandou que Marineusa não aparecesse mais. Começou então a briga pela separação dos irmãos, que não durou muito. Em meio à briga, sua mãe chamava os vizinhos para ajudar a cessar, foi quando, em meio à multidão, apareceu Marineusa, desatando a chorar, recolheu suas lágrimas e mostrou aos irmãos um lindo cordão de gotas 
líquidas, como um colar, de lágrimas siamesas, alternadamente surgindo o rosto de Osório e de Irrisório. Ela tomou aquele colar e lançou ao redor dos irmãos, "beijou-os na face, levantou-se e saiu entre alas de muito espanto".

A lágrima neste conto reveste a sedução que a miúda Marineusa causa em Osório, fazendo-o crer que das suas lágrimas saía só a sua imagem; ele contentase e vai de encontro ao seu irmão, achando que ele que esta por trás da situação, ao final, em meio à briga, o poder da lágrima mostra-se presente, embora não esteja escrito o que acontecera depois do fato, temos aqui o entendimento de que tudo ficou bem, graças ao colar de lágrimas siamesas feito por Marineusa. Temos também, anterior a isso, o quão maravilhado Osório ficou ao receber uma lágrima de sua amada, obviamente sendo uma lágrima de tristeza, devido à desconfiança - tristeza e medo, pois entendemos que Marineusa estava com seus sentimentos confundidos - e, mesmo assim, ele maravilhou-se, como se o seu choro, sua tristeza fosse para ele e por ele, isso o levou a uma certa excitação e glorificação, tendo sua fêmea chorando para e pelo seu macho.

Em “As lágrimas de Diamantinha”, do livro Na Berma de Nenhuma Estrada e Outros Contos, fala-se sobre uma mulher que tinha uma grande facilidade em chorar. Era uma mulher comum e essa sua singularidade fez com que o seu ganancioso marido se aproveitasse disso para ganhar dinheiro, pois as pessoas iam até ela, de propósito, só para ouvi-la chorar. Mas, certo dia, apareceu um cliente um pouco diferente. Era um homem muito forte e vestido de mulher, e pedia para ela chorar por ele porque ele a amava e, pensando que ela não o amava, começou a vestir-se de mulher para poder estar mais perto dela. As lágrimas enrijecidas originam-se agora da Diamantinha-mulher, que esvaziava suas próprias tristezas para dar lugar ao amor que chegara pela aparência de um(a) "colega do mesmo género", pois até então se produzia a Diamantinha-lagrimeira. Diamantinha-mulher tece seu "rosário de lagrimonas" em sintonia com seu inconsciente, com a água simbolizando a purificação e um 
(re)encontro consigo mesma. Pois, na realidade, ela também gostava de Florival e para provar isso ela deu-lhe as suas últimas lágrimas, que se transformaram em diamantes. Em seus "choros de diamantes" temos por símbolo a perfeição, que seria o diamante; na tradição ocidental, ele representa "a sabedoria universal, a incorruptibilidade e a realidade absoluta". Já para o budismo tântrico, “a inalterabilidade e o incrível poder espiritual"; no tibetano, "a clareza, a irradiação, a glória o gume da iluminação" (CHEVALIER; GHEERBRANT, 1996: 338).

As lágrimas desta choradeira remete-nos à purificação. Em Diamantinha, vemos a sensibilidade perdida e massacrada diante da violência dos corpos urbanos, e a velocidade de exploração - como seu marido propôs -, o marketing da humanidade, o exercício das relações por meio do comércio. O homem se endurece totalmente e não reconhece e sequer encontra a sensibilidade em si mesmo, no entanto, necessita de outro ser para que se sensibilize em seu nome como percebemos nas pessoas que vindas de longe para que Diamantinha chore por elas. A mídia cria pessoas, ícones, válvulas de escape de uma humanidade solitária e enrijecida. "Tombava uma chuvinha leve, simulando o fluir da terra para o céu. E Diamantinha, braços abertos, ajuntava gotas em seu peito choradeiro." (COUTO, 2003). Diamantinha e Florival são agora iguais, sem diferenças ou contraposições, vemos um homem e uma mulher que podem ser dois homens, ou duas mulheres, do ponto de vista simbólico, traz em si, ao mesmo tempo, masculino e feminino, como o sol e a lua, Yang e Yin, o espírito e a alma, fogo e a água, etc. Ainda que a asserção de que a "alma é uma combinação dos princípios feminino e masculino" e de que "o sexo indica não só a dualidade do ser, mas a sua bipolaridade e a sua tensão interna." (CHEVALIER; GHEERBRANT, 1996: 832; 598), são personagens reais. As lágrimas fizeram uma passagem simbólica de estágio desumano até o da clareza, iluminação e perfeição. 
Em "A Viagem da cozinheira lagrimosa" do livro Contos do nascer da Terra o mundo da cozinheira, resume-se ao óbvio: a cozinha. Logo de início, vemos uma explicação que compete à psicanálise, onde a cozinha "simbolizaria o local das transmutações alquímicas, ou das transformações psíquicas, isto é, um momento da evolução interior”. (CHEVALIER; GHEERBRANT, 1996). Esta seria uma interpretação simbólica ocidental, mas o conto dialoga com esse sentido quando o narrador heterodiegético descreve o local no universo africano em "Metida à sombra fumo, vapores. Nem sua alma enxergava nada, embaciada que estava por dentro. A mão tritacteava no balcão. $\mathrm{O}$ recinto era escuro, ali se encerravam voláteis penumbras" (COUTO, 2006. p. 23).

A cozinha, para a sociedade africana, é um local simbolicamente especial destacando-se do resto da casa e, em contrapartida, para os colonizadores, a cozinha é apenas um local de trabalho serviçal que, embora seja útil, é inferior pela ótica do ocupante branco.

O fato de Correia e Correia - ex-sargento colonial, reduzido à metade devido seu estado após batalhas - se sentir com meio corpo e de não conseguir saciar seu desejo sexual torna seu mundo incompleto. A cozinheira lhe é estranha e ele procura conhecê-la e, somente quando descobre o espaço choroso de Felizminha, acredita que: “A vida não tem metades. É sempre inteira”. Então, une-se a parte dela dando-lhe a mão em direção à terra dos coqueiros.

O elo que une os dois personagens são evidentemente as lágrimas da cozinheira que temperam a comida de seu patrão. Aprofundando o possível significado da lágrima remetendo água - que conduz espíritos, limpa a terra e promove a sobrevivência do homem - se une a simbólica alquimia do sal que afasta os maus espíritos, fertiliza a terra e preserva o alimento. Neste conto, vemos esta significação proposta por Chevalier e Gheerbrant (1996) que o sal que dá o sabor, purifica e simboliza a sabedoria, o alimento espiritual. 
A água que apaga, destrói, vivifica e regenera, é trazida pela sequência de gotas após gotas que cai "acertando o sal na lágrima" atingindo o objetivo. A gota "morre, evaporando-se, após ter dado testemunho: símbolo da dor e da intercessão" (CHAVALIER E GHEERBRANT, 1996).

A lágrima e a morte têm uma expressão simbólica no conto. Os olhos simbolizam tanto a percepção intelectual quanto a percepção da luz espiritual. O olho físico esquerdo, ligado à lua, refere-se à passividade e ao passado e o direito, ligado ao sol, é o da atividade do futuro. Nesse sentido, temos a indicação de que Correia e Correia teve mutilado o lado esquerdo da face, como é narrado no conto. Os olhos formam uma dualidade distintiva que é resolvida pela percepção unitiva do terceiro olho (frontal), o da sabedoria e o da visão interior, que é exteriorizado pelo olho do coração (CHAVALIER e CHEERBRANT, 1996: 654).

Por último, contrapondo o choro produzido ou induzido pela mulher, temos "Os machos lacrimosos" do livro O fio das missangas, em que vemos como a lágrima, historicamente e socialmente ligada a sexo feminino, tem um poder de liberdade nos homens, no bar de "Matakuane", homens estes que até então viviam de boemia e risadas, o que desgostava suas mulheres. Bar, onde se pregava a boemia e o ritual era festejar - as mulheres não precisavam de ritual para festejar a vida, pois elas eram a vida, ou a vida em festa - coisa de tribo, reminiscência atávica, pensavam as esposas dos boêmios.

"E assim se produziam eles, se consumiam elas" a imagem masculina neste conto atrela a casa do homem, como alegria e descontração, ao bar. Enquanto a da mulher, ao lar. Certo dia, um dos boêmios frequentadores do bar chegou em prantos, o que causou surpresa e aflição aos homens. Mal começara a se derramar em lágrimas Kapa-Kapa, a maioria já estava repassando um lenço que enxugaria lágrimas de um a um, passando então por todos. Após o fato, os homens começaram a pensar de uma forma diferente; no dia seguinte, chegaram 
com a mesma rotina, mas de forma diferente, houve então a sensibilidade do amigo que se expressou no dia anterior? Os homens do bar estavam interessados mesmo em escutar capítulos de tristeza, então pediram a Kapa-Kapa que divulgasse mais detalhes, resgasse véus, e então Kapa-Kapa ofereceu-lhes o drama, e todos choravam juntos.

Os baristas de "Matakuane" deixaram de lado o riso e a piada e passaram a compartilhar de lamentos, soluços e lágrimas. Até o mais macho de todos, Silvestre Estalone acabou por confessar: "Nunca pude imaginar, como é bom chorar!" Pensaram até em fundar uma associação de choradores. Mas chorar em público não seria uma boa ideia, devido ao que estaria em jogo: a masculinidade. O macho, em meio aos olhos da sociedade, não pode ser atrelado ao choro ou sequer a algo que remeta à sensibilidade. $\mathrm{O}$ acesso que a lágrima tem na figura masculina é represado pela sociedade e mais ainda: represado internamente pelos homens, por causa da sociedade e da vergonha. Vemos que entre os homens não existe problema de chorar, ainda afirmam "que para se valer o choro é melhor ainda quando chorado junto".

Conseguiu então Kapa-Kapa de forma a apresentar o choro, uma sensibilidade na imagem masculina dos boêmios, que mudaram até suas atitudes em relação as suas esposas, levavam-lhes flores, pareceram-lhes mais dedicados e atenciosos, e elas preferiam que isso ficasse assim, sem nenhum questionamento.

\section{Considerações Finais}

Precisamos ficar atentos para o que, de fato, essas situações nos dizem sobre a relação homem-mulher. Quando uma mulher chora e isso fascina um homem - como vemos no conto "A viagem da cozinheira lagrimosa" onde Correia e Correia de alguma forma se fascinou, se sensibilizou com a choradeira 
da cozinheira - ou o paralisa, ou the parte o coração, ou o faz simplesmente apaixonar-se por ela, ou ainda, o excita, o que estaria em jogo?

Poderíamos pensar que a mulher representada nos contos de Mia Couto utiliza esse artifício, suas lágrimas, como mais uma arma do seu arsenal sedutor, para prender, agarrar, excitar o homem. Vemos isso no conto "Lágrima para irmãos siameses", no qual a miúda de Osório o comove ao entregar-lhe uma lágrima que refletira seu rosto. Esse raciocínio, embora não totalmente incorreto, só parte da constatação de que os homens de fato são profundamente encantáveis, facilmente enfeitiçáveis pelo brilho lacrimejante do olhar feminino. Ou seja, a mulher pode usar esse encantamento nas engrenagens de seus jogos de sedução, mas isso não explicaria de onde vem a força desse encanto: ela brotaria do olhar da mulher e atingiria o homem, desarmado diante desse olhar? $\mathrm{Ou}$ a força que provoca essa miscelânea de afetos no homem partiria de dentro dele, de alguma parte insuspeita da constituição masculina que é acionada pelo rolar das lágrimas, e que implode as defesas do homem por dentro, de modo que estaria inerme diante desse olhar justamente por causa do ataque interno dessa força acionada pelo cair da lágrima?

Há na constituição masculina uma série de afetos poderosos que são invocados em sua relação com a mulher, ou melhor, com o feminino. Afetos sobre os quais o homem não tem controle e que é totalmente destoante daquilo que se espera do que é ser homem, e que, por isso mesmo, precisam ficar escondidos nas profundezas da alma masculina. No conto "Os machos lacrimosos", vemos a preocupação que os homens ficam em conter-se somente a chorar no bar, pois não podiam ser vistos, uma vez que o fato de serem vistos poderia "pegar mal" para eles. Esses afetos, como espíritos atávicos, seriam invocados das entranhas abissais da configuração masculina quando ele se aproxima demasiadamente de uma mulher, em ocasiões em que as 
subjetividades se tocam, como no momento em que a mulher chora diante dele, ou ainda, quando uma mulher chora por causa dele.

\section{Referências}

ANDRADE, Andressa. Gênero e História das Mulheres: diálogos conceituais. Disponível em: $<$ http://www.anpuhpb.org/anais_xiii_eeph/textos/ST\%2009\%20-\%20Andreza\%20de \%20Oliveira\%20Andrade.PDF>. Acessado em: 20 ago. de 2013.

BONNICI, Thomas. Conceitos-chave da Teoria Pós-colonial. Maringá: Editora da Universidade Estadual de Maringá, 2005a.

BRANDÃO, Izabel. "Ecofeminismo e Literatura: novas fronteiras críticas". In: BRANDÃO, Izabel; MUZART, Zahideé L. (Orgs.). Refazendo nós: Ensaios sobre Mulher e Literatura. Florianópolis: Ed. Mulheres; Santa Cruz do Sul: EDUNISC, 2003. p. 461473.

CANTARIN, Márcio. M. Por uma Nova Arrumação do Mundo. São Paulo: Cultura Acadêmica, 2012.

CHEVALIER, Jean; GHEERBRANT, Alain. Dicionário de Símbolos. Editora José Olympio, 2009.

CORACINI, Maria José. A celebração do outro: arquivo, memória e identidade: línguas(maternas e estrangeiras), plurilinguístico e tradução. Campinas,SP: Mercado de Letras, 2007.

COUTO, Mia. Estórias Abensonhadas. Rio de Janeiro: Editora Nova Fronteira, 1996.

. Cada Homem é uma raça. Lisboa: Caminho, 1997a.

. Contos do nascer da Terra. Lisboa: Caminho, $1997 \mathrm{~b}$.

. Na berma de nenhuma estrada. Lisboa: Caminho, 2004.

. O fio das miçangas. Lisboa: Caminho, 2009.

GARCIA, Neiva. Uma reflexão sobre a relação simbólica entre a água e o tempo na contística de Mia Couto. Disponível em: <http://www.lume.ufrgs.br/handle/10183/36014> Acessado em: 23 ago. 2013.

GUATTARI, Félix. As três ecologias. Tradução Maria Cristina F. Bittencourt. Campinas: Papirus Editora,1990.

HALL, Stuart. A identidade cultural na pós-modernidade. Rio de Janeiro: DP\&A, 2003.

LOURO, Lopes, Guacira. O corpo educado: pedagogia da sexualidade. Belo Horizonte 2000 $2^{\mathrm{a}}$ Ed. Autentica Editora.

SCOTT, Joan. "Gênero: uma categoria útil de análise histórica”. Educação \& Realidade. Porto Alegre, vol. 20, nº 2,jul./dez. 1995, pp. 71-99.

Nau Literária • vol. 09, n. $01 \cdot$ O efeito das lágrimas como fator de mudança do gênero masculino - um estudo de alguns contos de Mia 
WHITMONT, Edward C. Retorno da Deusa. São Paulo: Summus Editorial, 1991. 